\title{
Innovative transport technologies for transportation along the Northern Sea Route
}

\author{
Anton Alpatov ${ }^{1 *}$, Vladimir Zyryanov ${ }^{1}$, Ekaterina Alpatova ${ }^{2}$ and Julia Markarian ${ }^{1}$ \\ ${ }^{1}$ Don State Technical University, 1, Gagarin Sq., 344003, Rostov-on-Don, Russia \\ ${ }^{2}$ State University of Management, 99, Ryazansky prospect, 109542, Moscow, 109542, Russia
}

\begin{abstract}
The article is devoted to the study of innovative transport technologies for the transportation of liquefied natural gas by sea along the Northern Sea Route. The attention of the researchers was directed to the study of innovative mooring technologies in the conditions of the Far North. In the case of cargo transportation of gas along the Northern Sea Route, there is a need for continuous movement in view of the peculiarities of the Arctic Ocean and the danger of icing and stopping the cargo flow. To ensure the continuity of the cargo flow along the Northern Sea Route, it is necessary to provide refueling of sea transport, for this purpose, the introduction of an innovative system of hydraulic magnetic fenders is proposed. The application of this innovative technology consists in the use of electromagnetic equipment for the fender system when bunkering at sea on the "ship to ship" principle and the port harbor instead of the traditional mooring principle. It is used to improve the mooring process several times, which leads to increased economic efficiency and additional safety of crew members, and as an additional means of overcoming the ice barrier, which is a feature of the Northern Sea Route.
\end{abstract}

\section{Transportation of natural liquefied gas by sea}

The relevance of the use of liquefied natural gas (LNG) is increasing every year and is associated with the growing role in the development of the economy of many countries of the world, and the feasibility of its use is determined by the cost-effective of sea cargo transportation and, as a result, the mandatory safety of gas transportation by shipping. The most important problem of international trade in LNG, as raw materials for the chemical industry and fuel, is the method of delivering them from the production areas to the areas of use [1]. Countries that do not have gas deposits, and are separated by sea basins, for example: such as Japan, the EU countries, as well as most of the Caribbean countries are forced to resort to the services of sea transport, as the transportation of LNG has a huge number of advantages: the cost of ships per unit of cargo is significantly less than other modes of transport, the cost of transportation is several times lower than rail, and, many times more economical than road transportation, the only option for cargo delivery, which is the cheapest to the transportation of LNG by sea with respect to the pipeline delivery. Marine LNG carriers have a large cargo capacity in comparison with the previously listed methods of

* Corresponding author: author@email.org 
transportation, and one of the most important advantages is the unlimited sea and ocean routes.

\subsection{Peculiarities of transportation of natural liquefied gas along the Northern Sea Route}

Currently, there are two major sea routes - The Southern Sea Route (SSR) and the Northern Sea Route( NSR), and the most popular in the world of sea transportation until some time ago was the SSR, but the problem of crossing the Suez Canal, associated with the difficulty of uninterrupted movement of cargo ships and high financial costs for transit, puts the NSR in a priority position, creating conditions for the effective development of a new more promising transport route, as well as, as a strategic priority of Russia in the organization of transport cargo flows [2] and, (due to claims to the maritime territories of the Far North from foreign countries which also have rich sources in gas production and big powers), the full development of the Northern Sea Route plays a huge role also as a military value. In view of the fact that the Russian Federation is currently the owner of the largest icebreaker fleet in the world, there are all the necessary conditions for taking a leading position in the development of this transport artery of the planet [3]. The movement of vessels on the NSR is regulated by the legislation of Russia, the report on the activities on the NSR area is provided daily by the captain of each vessel, and if necessary, during the winter navigation, use icebreaker wiring in coordination with the ship-owner organization "Rosatomflot" by a nuclear icebreaker along the routes of the Northern Sea Route. But, due to the increased popularity of the NSR water area, the demand for icebreaking services has increased, in this regard, there is a shortage of nuclear icebreakers to accompany the merchant fleet, and the strategic vector for the development and full development of the NSR for the Russian Federation should be formed in increasing this number in order to capture the primacy in international trade using a complex of shipping routes.

We will focus in more detail on the consideration of the features of the transportation of natural liquefied gas through the NSR. The production of natural Arctic gas of the Russian Federation is carried out mainly on the Yamal Peninsula, transportation is carried out by means of sea vessels specially designed for the transportation of natural gas-gas carriers to the countries of Asia [4] and the European Union [5] by liquefying it to a temperature of 161.45 C. The climatic features of transportation along the NSR require transportation in a mandatory bundle with a nuclear icebreaker with an ice thickness of more than $3 \mathrm{~m}$, in addition, there is an iceberg hazard [6]. Gases are more profitable to transport in the form of liquids, since the weight of LNG is about 650 times greater than its weight in the gas stage state.

The temperature at which LNG can be condensed is correlated with the pressure at which the gas is located. Consequently, the combination of gas transport pressure and temperature is taken into account during the design and equipment of LNG transport vessels. A significant portion of commercial gases have a density that is about more than half of water density, and cargo capacity will be established using the useful volume of the ship's cargo tanks. Considering the temperature characteristics of the cargo, the pressure at which LNG is transported, and the low density of the transported cargo, the design of gas carriers is a vessel with a high freeboard and a relatively small draft. Such a unique design of vessels of this type, interacting comprehensively with the free surface of liquefied gas, deserves special attention to the stability of vessels of this type. Gas carriers of the refrigerated type (Fully refrigerated ships) - vessels of this type carry LNG at almost atmospheric pressure and are designed to transport large loads of cargo.

At the present stage of development of natural gas transportation, the modernization of supply vessels, such as bunkering vessels, with modern innovative technology of hydraulic 
electromagnetic fenders (figure 1) for the operational implementation of mooring and loading and unloading processes is becoming more relevant.

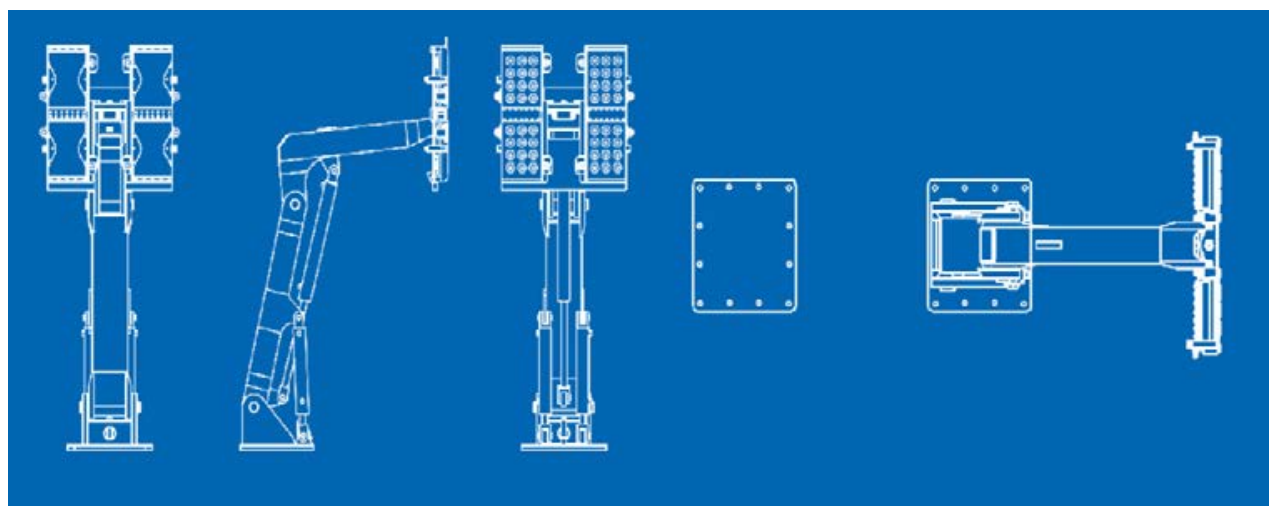

Fig. 1. Innovative hydraulic electromagnetic fenders system (Innovative Mooring Systems «Dock Lock») [8].

The main characteristics of the innovative system of hydraulic electromagnetic fenders are shown in Table 1.

Table 1. Characteristics of the innovative system of electromagnetic fenders «Dock Lock»

\begin{tabular}{|c|c|}
\hline Factor & Factor value \\
\hline Holding force & $\begin{array}{r}200 \mathrm{KN} \text { (during the excitement) } \\
40 \mathrm{KN} \text { (during still water) }\end{array}$ \\
\hline $\begin{array}{c}+450 \mathrm{~mm} \\
\text { Acceptable offset }\end{array}$ & $2000 \mathrm{~mm}$ \\
\hline $\begin{array}{c}\text { Distance between mooring } \\
\text { vessels }\end{array}$ & $+/-5^{\circ}$ \\
\hline Roll/Trim & $16 \mathrm{KW}$ \\
\hline Voltage & $1600 \mathrm{~kg}$ \\
\hline $\begin{array}{c}\text { Weight of the "Dock Lock" } \\
\text { system» }\end{array}$ & $2000 \mathrm{~mm}$ \\
\hline Height & $1060 \mathrm{~mm}$ \\
\hline Width & $1600 \mathrm{~mm}$ \\
\hline Length &
\end{tabular}

Before any operations of this kind, it is recommended to organize and think through in detail the entire procedure from beginning to end. Prior to the operation, the captains of the two vessels exchange information via satellite Internet, such as:

- main dimensions of the vessel;

- height of the manifold;

- amount of fender protection;

- the procedure of approach and mooring to the ship;

- the exact position (coordinates) of the meeting of the vessels.

The most common (but not limited to) risk factors are:

- environmental conditions;

- available water space (sea depth, tides, free space);

- communication problems;

- training and briefings for the crew;

- size and location of the vessels involved;

- LNG risk factors. 
In our study, a symbiosis between traditional and innovative methods of bunkering is carried out. In the peculiarities of the climate of the NSR water area, such a risk factor as environmental conditions is decisive, and in this regard, it is necessary to introduce an innovative mooring complex into the traditional mooring processes of gas carriers and supply vessels.

\subsection{Innovative system of hydraulic electromagnetic fenders for supply vessels on the NSR}

To improve and facilitate the work of the crew of a transport vessel, increase the economic effect and reduce the risk of injuries during cargo operations at sea on the move or at anchor, our study suggests the use of an innovative system of electromagnetic automatic mooring "Dock Lock" [8].

The principle of operation of this system consists of the ability to bring mooring operations to an automated mechanism. The electromagnets extend to the hull of the vessel and are fixed in different positions relative to each other, which entails the ability to hold the other vessel even when the draft decreases or increases. Next, the diagram (figure 2) shows the location of the innovative mooring system during navigation in operating mode, (figure 2a) - side view and (figure $2 \mathrm{~b}$ ) - top view.

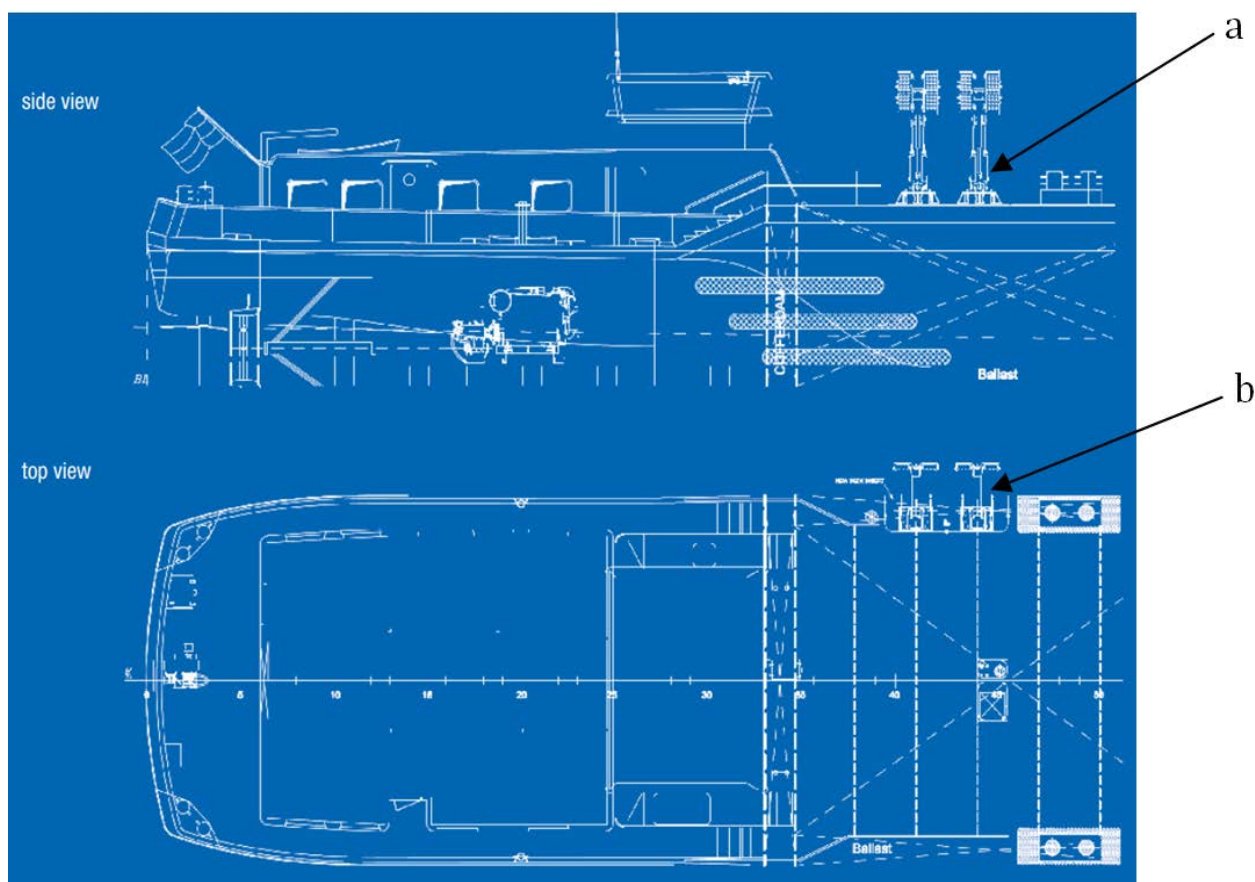

Fig. 2. General arrangement while engaged in bunkering operation by Innovative hydraulic electromagnetic fenders system (Innovative Mooring Systems «Dock Lock»): a- side view, b- top view [8].

This system uses an electromagnetic module connected to three hydraulic cylinders mounted in a solid frame. Behind the frame is a central control unit and communication modules. Then, after attaching the innovative mooring system between the vessels, the holding magnetic force for the maximum load is automatically calculated. If this effort is satisfactory, the system reports a ship safely moored. 
Once properly attached, the system switches to "resistance" mode. To do this, a system of control over the dynamic movements of ships begins to work, which compensate for the pitching and thus control all external factors of influence. Mooring after the end of cargo operations and preparing for sailing takes seconds and is performed by simply pressing the "Safety check" button.

The ship's crew can always interfere with the operation of the equipment and switch it to manual control on the spot, as well as remotely from a computer. The location of the innovative mooring system during navigation in the "rest" mode is shown in the diagram (figure 3): $\mathrm{a}$ - side view, $\mathrm{b}$ - top view.

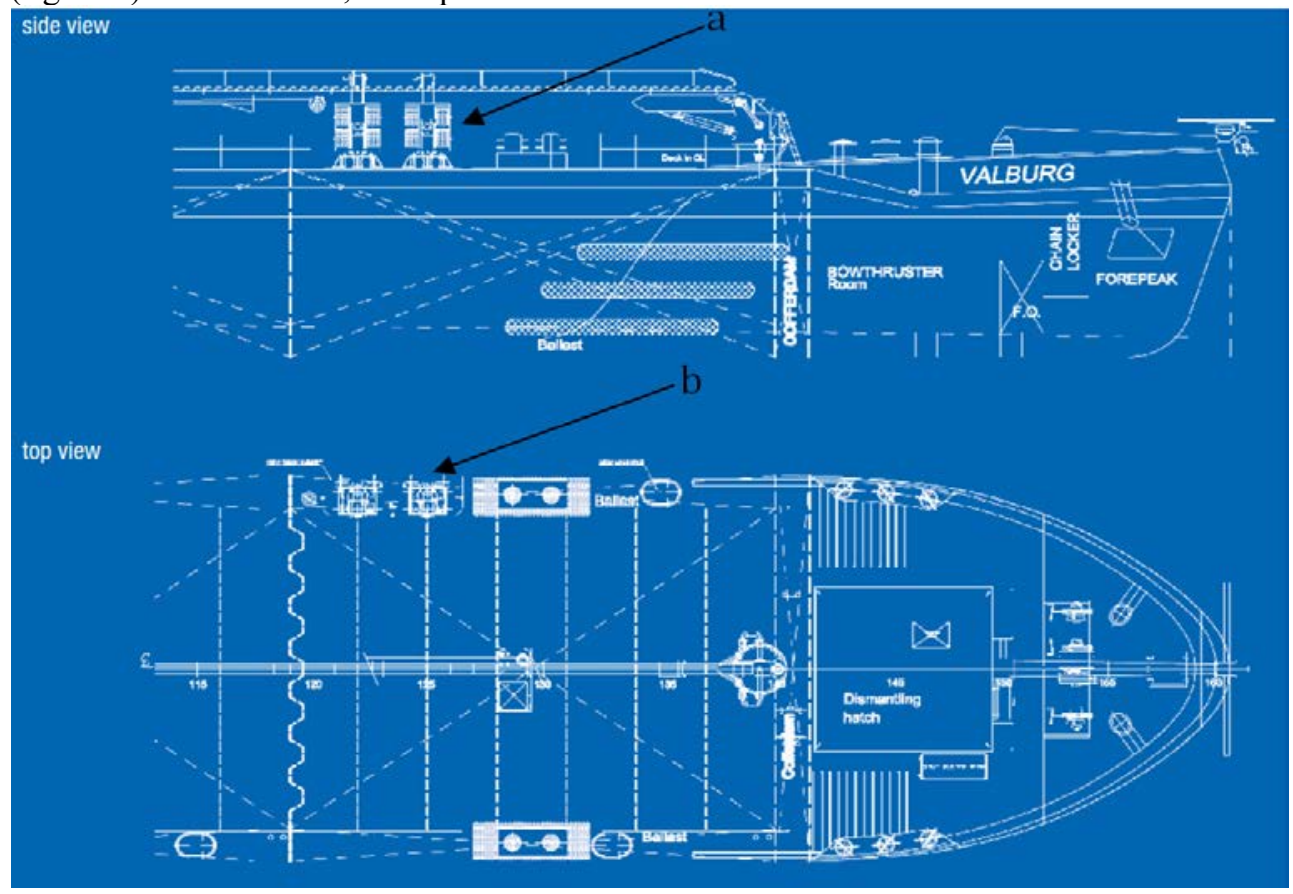

Fig. 3. General arrangement while engaged in bunkering operation by Innovative hydraulic electromagnetic fenders system (Innovative Mooring Systems « Dock Lock »): $a-$ side view, b - top view [8].

The use of this system contributes to [8]:

- increased safety $[9,10]$;

- increase efficiency;

- reliability of use in the low-temperature mode of high latitudes [11];

- overcoming the icing of the ship's hull by reducing the time required for bunkering operations by using an innovative mooring system.

Fully automated mooring operations neutralize the risks [10] of damage and death of crew members, eliminating the steel mooring ropes, and the crews will be able to constantly monitor the holding force and the position of the equipment in real time. The "Dock Lock" system guarantees the performance and reliability of the operation under any circumstances [12]. Automatic mooring operations require 10 seconds for mooring and 5 seconds for unmooring, which will significantly help the crews in carrying out cargo operations.

By reducing the time of mooring processes for bunkering operations at sea or in port harbors of the Arctic water area, fuel consumption is reduced and there is a fairly large time saving, since the classic operation takes about 1.5-2 hours, which will significantly increase the economic coefficients for ship-owners and charterers. 
Minimal material wear compared to classic steel ropes also plays an important role in the design of this system, but as with any implementation, so with this equipment there are a number of disadvantages:

- high cost;

- low flexibility: if the equipment breaks down, there will be no quick alternative replacement (compared to the relatively easy replacement of the mooring end, if it breaks);

- the possibility of deformation of the board in the conditions of the spin wind.

On board all vessels, there is a duplication of all the main systems, such as: generator system, navigation equipment, fire extinguishing systems and rescue equipment, including mooring equipment, should be duplicated with traditional systems for mooring operations in the form of a classic arrangement of mooring winches, in case of failure of innovative systems.

\section{Conclusion}

In this article studies the implementation of an innovative system of hydraulic electromagnetic fenders in the bunkering of marine vessels carrying natural liquefied gas by NSR routes. The structure and principle of operation of the innovative bunkering system are considered, the main characteristics are analyzed, positive and negative factors for safer bunkering operations "ship to ship" are highlighted. The introduction of an innovative bunkering system does not negate the presence of a traditional mooring system, as a backup on a sea vessel. In this paper, the ways to increase efficiency through the introduction of an innovative hydraulic electromagnetic system "Dock Lock" are identified. The use of an innovative electromagnetic fender system in bunkering operations provides additional safety for ship crew members. The introduction of the innovative bunkering system under study increases economic efficiency by reducing the required time for the procedure, which is especially important for charterers and ship-owners. The use of an innovative system of hydraulic electromagnetic fenders during bunkering can contribute to the improvement of one of the priority, socially significant factors - the environmental one, and the improvement of the environmental situation on the routes of the Northern Sea Route is of great importance for future generations of the planet.

\section{References}

1. W. Slaczka, The possibilities of simulation research of the risk assessment of LNG tanker manoeuvring in the selected area / W. Slaczka, A. Anczykowska, A. Adamkiewicz // 17th international multidisciplinary scientific geoconference SGEM 2017, Albena, Bulgaria, 29.06.2017. - Albena, Bulgaria: OOO STEF92 Tehnology, 793-800 (2017).

2. Hua, Xu, Zhifang, Yin The optimal icebreaking tariffs and the economic performance of tramp shipping on the Northern Sea Route // Transportation Research Part A: Policy and Practice, 149, 19.05.2021, 76-97 (2021). doi.org/10.1016/j.tra.2021.04.017.

3. Chi Zhang, Di Zhang, Mingyang Zhang, Xiao Lang, Wengang Mao An integrated risk assessment model for safe Arctic navigation. 142, December 2020, 101-114 (2020). doi.org/10.1016/j.tra.2020.10.017.

4. Lei Dai, Danyue Jing, Hao Hu, Zhaojing Wang An environmental and techno-economic analysis of transporting LNG via Arctic route, 140, April 2021, 56-71 (2021).

5. Lavissière, Alexandre, Sohier, Romain, Lavissière, Mary C. Transportation systems in the Arctic: A systematic literature review using textometry. Transportation Research Part 
A: Policy and Practice1, 141, October 2020. 130-146 (2020). doi.org/10.1016/j.tra.2020.09.003.

6. Roozbeh Panahi, Adolf K.Y.Ng, Mawuli Afenyo, Yui-yipLau Reflecting on forty years contextual evolution of arctic port research: The past and now. Transportation Research Part A: Policy and Practice1, 144, February 2021. 189-203 (2021). doi.org/10.1016/j.tra.2020.12.001.

7. Kulitsa, M. Duality in lng tank-pressure behaviour and its relevance for ship-to-ship transfers to floating storage and regasification units / M. Kulitsa, D. A. Wood // Advances in Geo-Energy Research, 4. - No 1, 54-76 (2020).

8. Innovation Automated Mooring System Brochure // Mampaey, Mampaey Offshore Industries, 2004. 8

9. H. Fan, Safety philosophy and risk analysis methodology for LNG bunkering simultaneous operations (SIMOPS): A literature review / H. Fan, H. Enshaei, S. Gamini Jayasinghe // Safety Science, 136, 105150 (2021).

10. J. Wu, Y. Bai, H. Zhao [et al.] A quantitative LNG risk assessment model based on integrated Bayesian-Catastrophe-EPE method, Safety Science, 137, 105184 (2021).

11. Analysis of the modes of fuel operation of river transport vessels used for deliveries to the Northern regions of Russia, Saint-Petersburg, 15-19 April 2019, 17-20 (2019).

12. B. Jeong, B. S. Lee, P. Zhou, S. M. Ha Determination of safety exclusion zone for LNG bunkering at fuel-supplying point, Ocean Engineering, 152, 113-129 (2018). 